\title{
Lasers in dentistry: an unceasing evolution
}

\begin{abstract}
Lasers were introduced in dental practice by Miaman in 1960, and since then have come a long way in enhancing the efficacy of the traditional treatment methods. From diagnosing a simple caries to the planning and treatment of the very complicated lesions or malignancies, lasers are by far taking over the conventionally followed dental techniques. Every specialty of dentistry has been vastly affected with the use of laser technology. The capability of providing minimally invasive procedures without any distress to the patient has made a huge impact on the delivery of dental care. This practice will endure as the laser technology promises to develop and evolve unceasingly. The resolution of this paper is to deliver an overview of various laser applications in dentistry and its pros over the conventional approaches.
\end{abstract}

Volume 10 Issue $6-2018$

\author{
Mithra N Hegde,' Payal Garg, ${ }^{2}$ Nidarsh D \\ Hegde $^{3}$ \\ 'Vice Principal and Head of the Department, Department of \\ Conservative Dentistry and Endodontics, A.B. Shetty Memorial \\ Institute of Dental Sciences, India \\ ${ }^{2}$ Post Graduate Student, Department of Conservative Dentistry \\ and Endodontics, A.B. Shetty Memorial Institute of Dental \\ Sciences, India \\ ${ }^{3}$ Oral and Maxillofacial Surgeon, India
}

\begin{abstract}
Correspondence: Mithra Hegde, Vice Principal and Head of the Department, Department of Conservative Dentistry and Endodontics, A.B. Shetty Memorial Institute of Dental Sciences, Mangalore-5750 I8, India, Tel +9 I-98452844II,

Email drhegdadentist@gmail.com
\end{abstract}

Received: July 31, 2018 | Published: December 10, 2018

\section{Introduction}

Since the introduction of lasers in dentistry in 1960's, there has been an outbreak of its clinical applications in the field. ${ }^{1}$ Lasers are stipulated for an extensive variety of procedures in dental practice on account of the simplicity, efficiency, explicitness, comfort and value over the traditional modalities. ${ }^{2,3,4,5}$ The word 'Laser' being an abbreviation for Light Amplification by Stimulated Emission of Radiation, amplifies and yields a high directional, concentrated, monochromatic and coherent beam. In dentistry, the laser light is delivered from the laser to the target tissue via a fiberoptic cable, hollow waveguide, or articulated arm (Table 1).

Table I Common types of lasers used in dentistry

\begin{tabular}{llll}
\hline Laser type & Construction & Wavelength(s) & Delivery system(s) \\
\hline Argon & Gas Laser & $488,515 \mathrm{~nm}$ & Optical fiber \\
KTP & Solid State & $532 \mathrm{~nm}$ & Optical fiber \\
Helium-neon & Gas Laser & $633 \mathrm{~nm}$ & Optical fiber \\
Diode & Semiconductor & $635,670,810,830,980 \mathrm{~nm}$ & Optical fiber \\
Nd:YAG & Solid State & $1064 \mathrm{~nm}$ & Optical fiber \\
Er, Cr:YSGG & Solid State & $2780 \mathrm{~nm}$ & Optical fiber \\
Er:YAG & Solid State & $2940 \mathrm{~nm}$ & Optical fiber, Waveguide,Articulated arm \\
CO2 & Gas Laser & $9600,10600 \mathrm{~nm}$ & Waveguide,Articulated arm
\end{tabular}

Once deemed as a complicated technology with restricted usages in clinical dentistry, there is now a beaming understanding of the practicality of lasers in the armamentarium of the contemporary dental practice, where they can be utilized as an adjunct to regular practices.

\section{Types of laser}

Lasers used in dentistry can be categorized according to wavelength (Figure 1), physical construction of laser, type of medium used, tissues on which it is applied and based on the extent of hazard following accidental exposure. ${ }^{7}$ The components of a laser including the Laser medium, optical cavity, energy source are depicted in Figure $2.5,2$

\section{Neodymium}

Yttrium Aluminium Garnet (Nd:YAG) Laser: Very active surgical laser for cutting and coagulating dental soft tissues as the wavelength is vastly absorbed by the pigmented tissue. When used in non contact defocused mode, it can penetrate several millimeters, which helps in homoeostasis treatment of aphthous ulcers or pulpal analgesia. ${ }^{8}$

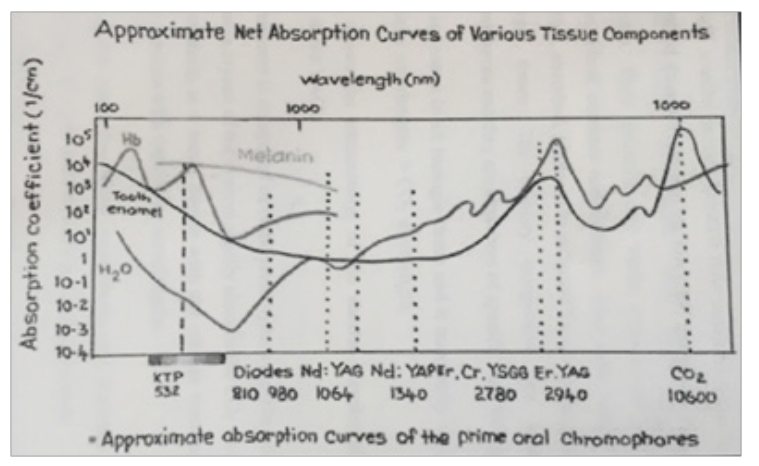

Figure I Various types of lasers and their corresponding working lengths. 


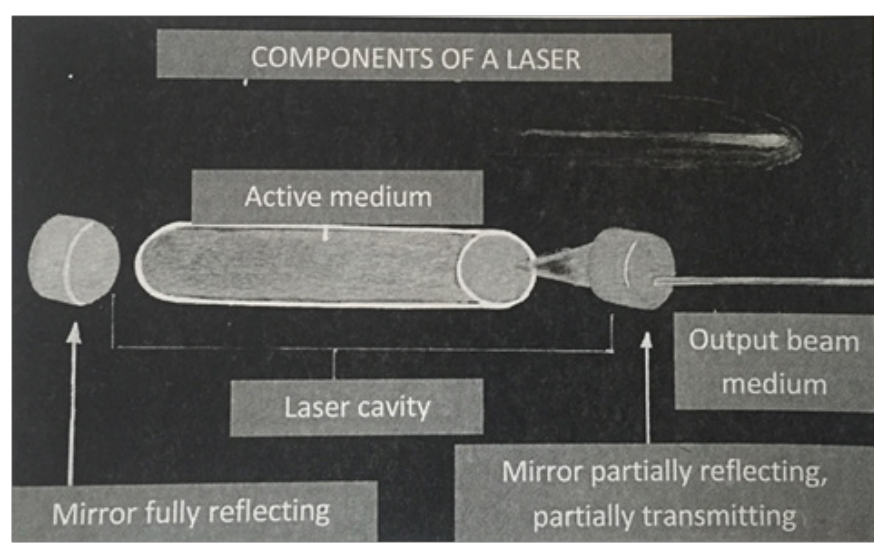

Figure 2 Laser Component.

\section{Carbon dioxide laser}

Used to attain sterilization, scar formation and minimizes the hematoma formation as it leaves behind carbon residues called Char that act as dressing and help in sterilization. ${ }^{9}$ Great affinity for water, can smoothly cut and coagulate soft tissue. Disadvantages are its hard tissue damaging and expensive nature.

\section{Diode laser}

Also called Semiconductor or Low Level Laser. In a diode laser, the active medium is sandwiched between silicon wafers..$^{10}$ Wavelengths are poorly absorbed by dental hard tissues, hence soft tissue surgeries can be executed securely. Main benefit being smaller size, portable instrument and can also activate fibroblastic proliferation at low energy levels. ${ }^{11,12}$

\section{Argon lasers}

In dental practice, two emission radiations are used: $488 \mathrm{~nm}$ (blue) and $514 \mathrm{~nm}$ (blue green). Used in periodontics as they possess bactericidal properties against Prevotella intermedia and Porphyromonas gingivalis. ${ }^{10}$

Erbium Laser: Two separate wavelengths form the Erbium 'family', Er, Cr: YSGG (Yttrium Scandium Gallium Garnet) lasers and Er: YAG (Yttrium Aluminium Garne) lasers. ${ }^{6}$ Preferred laser for dental hard tissues as it has greatest absorption of water. It can also be utilized for soft tissue ablation. ${ }^{13}$

\section{Low level laser therapy (LLLT)}

Low level lasers are usually smaller, inexpensive and operate in the milliwatt range, 1-500 milliwatts. This therapy is called 'Biostimulation' or 'Biomodulation'. Employed for use at Postextraction sites, Dentinal hypersensitivity, Temperomandibular disorders.

\section{Application of lasers}

\section{Lasers as a diagnostic aid}

Detection of dental caries: The conventional probing the enamel with dental probe is not recommended anymore as it destroys the enamel surface and causes cavitations. ${ }^{7}$

Diagnodent, a $655 \mathrm{~nm}$ diode laser helps in the detection of incipient caries and this is called laser-induced fluorescence. Greater fluorescence is demonstrated by the carious lesions, which helps in distinguishing it from the healthy tooth structure. Detects interproximal, occlusal and occult lesions beneath fissure sealants. ${ }^{14-16}$

\section{Lasers used as a research tool}

Confocal laser scanning microscopy: It has been recognized as a non damaging tool for observing the sub-surface tomography of enamel and dentin hard tissues. Real time assessment of demineralization and remineralization processes can also be done. The high cost still limits its implementation in dental practice. ${ }^{17}$

\section{Spectroscopic analysis of tooth structure}

Laser Induced Breakdown Spectroscopy (LIBS) was concluded as a tool in 2001 for real time in vivo and in vitro identification of carious teeth. ${ }^{18}$

\section{Lasers in endodontic diagnosis}

Laser Doppler Flowmetry for assessment of pulpal blood flow: $\mathrm{He}-\mathrm{Ne}$ and GaAlAs semiconductor diode lasers at a low power of 1 or $2 \mathrm{~mW}$ are used to detect the changes in red blood cells flux in the pulp tissue. Also assists in determining revascularization of traumatized teeth but the high initial set up costs limits its use. ${ }^{19}$

Heat stimulation to check pulp vitality: The hot gutta percha method to assess vitality cannot always be performed due to thick enamel and dentin or the great perception of pain of dental pulp tissue. In comparison to the traditional electric pulp tester, the pulsed stimulation by Nd:YAG laser produces mild and tolerable pain. ${ }^{20}$

Differential diagnosis of pulpitis by laser stimulation: In the case of acute pulpitis, instantly after laser application, pain is induced and continues for more than 30 seconds after interruption of stimulation. In normal pulp on stimulation of $\mathrm{Nd}$ : YAG laser pain is produced within 20-30seconds and disappears after interruption. ${ }^{21}$

Dentinal hypersensitivity (DH) and pain management by lasers: It is one of the most familiar complaints in dental practice. Low level Laser therapy has been exercised for the treatment of DH. It depends upon laser induced changes to neural transmission networks within the dental pulp instead of alterations to the exposed dentine surface, as in case of conventional methods. ${ }^{10}$

Caries, restoration removal and cavity preparation by lasers: Without substantial harm to tooth structure, the Er: YAG lasers have been successfully used in adult and pediatric patients for caries removal and preparation of cavity. It eliminates caries in the enamel and dentine by ablation, without the unfavorable effect of increased temperature near pulp, in the absence of water cooling using low level laser therapy. It also assists in removal of faulty composite restorations and cements. ${ }^{22,23}$

Etching by lasers: Er, Cr: YSGG has been used as a substitute for acid etching of enamel and dentine. Laser etched surfaces show microirregularities and no smear layer. ${ }^{24}$ As compared to the traditional acid etching, the adhesion to dental hard tissues is inferior after laser assisted etching. . $^{25,26}$

Calculus removal using lasers: The bacterial porphyrins in calculus emit a strong fluorescence signal, which can be utilized to control the Er: YAG laser for scaling. These lasers are vastly bactericidal against specific periodontal pathogens namely $\mathrm{P}$. gingivalis and Actinobacillus actinomycetemcomitans. ${ }^{10}$

Biopsy using lasers: Accurate intraoral biopsies can be performed using lasers of all dental wavelengths. Due to nominal discomfort and trauma with outstanding hemostasis, sutures post biopsy are rarely required. 'Laser Artifact' is a tissue effect seen beside the incision which varies and depends on the thermal effect of the specific laser used. ${ }^{62}$ 
Esthetics and lasers: Thanks to lasers, it is now possible to alter gingival tissue conservatively to craft a more natural, symmetrical and harmonious appearance. Thus, the use of lasers has advanced the world of esthetic dentistry in a revolutionary way.

Gingival cosmetic resculpting: The $\mathrm{CO}_{2}$ or Diode laser can be used to accurately shape the tissues to ideal contour in case of papillary hypertrophy and gingival tissue asymmetry. Slow to medium pulsed mode ( 2 to 10 pulses/second) permits the operator to vertically remove the amount of tissue needed and get the required contour. ${ }^{27}$ Gummy smile correction by gingivoplasty using lasers has shown excellent esthetic results. ${ }^{28}$

Gingivectomy for tissue hyperplasia: The unessential hyperplastic tissues can be excised using the $\mathrm{CO}_{2}$, diode lasers by incising the location of ideal gingival margin in a focused mode. The procedure is bloodless with a more accurate control than electrosurgery and no requirement of a postoperative dressing. ${ }^{27}$

Frenectomy: Diode, Argon, $\mathrm{CO}_{2}$ and Nd: YAG lasers when used in focused, uninterrupted mode or pulsed, defocused mode can help excise the frenum. The procedure is blood-less with excellent healing and exclusion of sutures. 29

Gingival troughing: Bloodless gingival troughing done before taking impressions help eradicate the need for vasoconstrictors and retraction cords. The tissue is 'ledged' to expose the preparation margin by placing the laser tip below the gingival crevice height. ${ }^{29}$

Bleaching assisted by lasers: Aims to get the definitive power bleaching process using the most competent energy source while eluding side effects. $488 \mathrm{~nm}$ argon laser is used to excite hydrogen peroxide molecule and thus augments bleaching by photo-oxidation of colored molecules in the teeth resulting in eventually whitened tooth surface. ${ }^{30}$ The procedure is rapid due to greater concentration of active ingredient and acts as a jump start for difficult stains. The high cost and vast amount of time consumed along with post operative sensitivity are however unfavorable in few cases. ${ }^{31}$

Lasers in pediatric dentistry: Gutknecht et al postulated the effectiveness of $\mathrm{CO}_{2}$ lasers in pulpotomy in pediatric patients. The main benefits of using $\mathrm{CO}_{2}$ laser are sterility, preservation of pulp vitality, healing the exposed area and ensuring an intimate contact between the pulp and capping agent by reducing inflammation and stimulating dentinogenesis.

Caries removal, Coagulation of exposed pulp,pulpectomy or pulpotomy can also be performed using Er: YAG and Er,Cr: YSGG lasers. $^{32}$

\section{Laser-assisted endodontics}

\section{Laser-activated irrigation:}

Laser activation of irrigants takes place mainly by photomechanical and photothermal mechanisms. The agitation of fluids in the root canal permits enhanced penetration of fluids into the corners of the root canal anatomy. The simultaneous increase in temperature accelerates chemical reactions, namely etching and protein dissolution. ${ }^{7}$

\section{Laser light effects on bacteria}

A photomechanical acoustic effect occurs when Erbium Laser energy is distributed with very short pulse durations in a liquid occupied environment. According to a recent study, a bacteria kill of $73 \%$ was observed when distilled water was activated by lasers for 30 seconds in an ex vivo infected root canal. ${ }^{7}$
Bacterial Reduction with Mid-Infrared Lasers: New researches have validated the capacity of Er: YAG lasers to eliminate endodontic biofilm from various species of bacteria.

Lasers in management of Endo-Perio Lesions: Pulp space therapy and regular non surgical subgingival periodontal therapy is done by diode soft tissue laser. The results were excellent with gain in the clinical attachment and no affects on the soft tissue profile. ${ }^{61}$

Photo-activated disinfection: A system has been integrated for endodontic purpose comprising of a small diode laser connected to a delivery fiber. This is based on the principle of Photodynamic Antimicrobial Chemotherapy in which the photosensitizer molecules attach to the bacterial membrane. ${ }^{5}$

Wound healing: Laser application at low doses (e.g., $2 \mathrm{~J} / \mathrm{cm} 2$ ) encourages proliferation while at increased doses (e.g., $16 \mathrm{~J} / \mathrm{cm}^{2}$ ) causes suppression. ${ }^{33,34}$ LLLT enhances healing and dentinogenesis after pulpotomy[35] and also assists healing in mucositis and oropharyngeal ulcer patients. ${ }^{36}$ Transformation in myofibroblasts after 24 hours of low level laser therapy of gingival fibroblasts has been proven. ${ }^{37}$

\section{Laser assisted photoactivated dye (PAD) disinfection}

DNA and membrane damage to the microorganisms is caused by the photochemical activation of oxygen by low level laser therapy. ${ }^{38,39}$ Major uses of PAD include disinfection of periodontal pockets, root canals, deep carious lesions and sites of periimplantitis. ${ }^{40,41}$

\section{Photodynamic therapy (PDT) for tumors}

This therapy has been used in the treatment of malignancies of oral mucosa. Positive results of PDT therapy for treatment of carcinoma in situ and squamous cell carcinoma have been reported, with response rate nearing $90 \%{ }^{42-44}$

\section{Apthous ulcer and post herpetic neuralgia}

$\mathrm{He}-\mathrm{Ne}$ low levels of laser energy are beneficial in providing pain relief and enhance healing by photostimulation of aphthous ulcers and recurrent herpetic lesions. ${ }^{45}$ During the tingling phase, photostimulation blocks the lesions before painful vesicles are produced, accelerates the healing time and reduces the recurrence of lesion. ${ }^{46,47}$

\section{E-model preparation by 3-D laser scanner}

Laser scanner can be utilized as a scanner for soft tissues and is a handy tool for its simplicity in application and creation of three dimensional images of dental structures. It is used to observe surgical ${ }^{48,49}$ and non surgical ${ }^{50,51}$ treatments in oropharyngeal areas.

\section{Analgesic effect of the laser}

Low level laser therapy on nerves supplying the oral structures reduces the firing frequency of the pain receptors. ${ }^{53}$ Wavelengths from $632 \mathrm{~nm}$ to $904 \mathrm{~nm}$ have been recognized as efficacious analgesia post oral surgeries. ${ }^{54,55}$ The pain associated with orthodontic tooth movement can be decreased by local irradiation with $\mathrm{CO} 2$ laser. A single episode of low level laser therapy (0.9-2.7 J) is vastly successful for apical periodontitis post root canal treatment and post extraction pain. ${ }^{55,56}$

\section{Nerve repair and regeneration}

Application of low level laser therapy has borne great results in accelerating the regeneration of inferior dental nerve tissue, harmed 
during surgical procedures. It decreases the production of inflammatory mediators and promotes neuronal maturation post injury. ${ }^{58,59}$

\section{Laser safety}

Lasers bring with them a vast risk of severe injury and high damage. The three pivots of laser safety are:

i. Manufacturing process of the instrument

ii. Operative the device properly

iii. Personal protection of the patient and the surgical team ${ }^{60}$

iv. The most crucial measure is protective eyewear by anyone near to the operating area including the patient and the operators (Figure 3). Accidental exposure to the non target tissue can be avoided by restraining access to the surgical zone, putting up warning signs, reducing the reflective surfaces and confirming the proper functioning of laser. High volume suction should be employed to evacuate any vapor plume. A designated Laser Safety Officer to regulate, supervises the proper usage of laser, maintain use of protective eyegears, and synchronize training programs for staff. 60

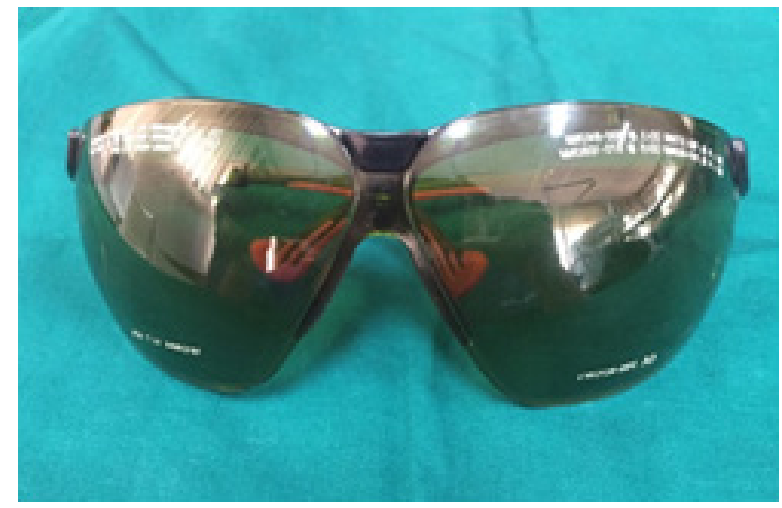

Figure 3 Safety measures in dental office while using lasers.

Protective Eyewear while using Lasers.

\section{Limitations of lasers}

It needs additional training and education for clinical usage and applications. Also the investment in its high cost and technology is a hurdle. Since different wavelengths are needed for various procedures, more than one type of lasers is needed in dental practice.

\section{Medicolegal considerations}

Lasers being used for conservative soft tissue surgery are considered within the horizons of recognized dental practice. Routine informed consent must be taken invariably in all cases prior to commencement of the treatment. Every operator should undergo a proper training program from a trustworthy provider.

\section{Conclusion}

In clinical dental practice, laser technology is at an elevated state of enhanced development up to the current time, and has great scope for the future. Laser based photochemical reactions possess high potential for further expansion, specifically to target particular pathogens and cells. The treatment planning and prognosis in clinical dentistry will experience a huge upgrade with the increased usage of lasers in the upcoming days. In true sense the advent of this technology has transformed the field of dentistry to a more painless, bloodless dentistry with instant results and more predictability.

\section{Acknowledgments}

None.

\section{Conflicts of interest}

The author declares there is no conflict of interest.

\section{References}

1. Maiman TH. Stimulated optical radiation in ruby lasers. Nature. 1960;187:493.

2. Frentzen M, Koort HJ. Lasers in dentistry: New possibilities with advancing laser technology. Int Dent J. 1990;40(6):323-332.

3. Aoki A, Ando $\mathrm{Y}$, Watanabe $\mathrm{H}$, et al. In vitrostudies on laser scaling of sub-gingival calculus with an erbium: YAG laser. $J$ Periodontal. 1994;65(12):1097-106.

4. Pelagalli J, Gimbel CB, Hansen RT, et al. Investigational study of the use of Er: YAG Laser versus dental drill for caries removal and cavity preparation - Phase I. J Clin Laser Med Surg. 1997;15(3):109-115.

5. Walsh LJ. The current status of laser applications in dentistry. Aust Dent J. 2003;48(3):146-155.

6. Verma SK, Maheshwari S, Singh RK, et al. Laser in dentistry: An innovative tool in modern dental practice. Natl $J$ Maxillofac Surg. 2012;3(2):124.

7. Pandey V. lasers in Operative Dentistry and Endodontics.

8. Nambiar KR. Lasers: Principles, Types and Applications. New Age International; 2006.

9. Darling CL, Fried D. Real-time near IR $(1310 \mathrm{~nm})$ imaging of $\mathrm{CO}_{2}$ laser ablation of enamel. Optics Express. 2008;16(4):2685-2693.

10. David CM, Gupta P. Lasers in dentistry: a review. International Journal of Advanced Health Sciences. 2015;2(8):7-13.

11. Moritz A, Gutknecht N, Doertbudak O, et al. Bacterial reduction in periodontal pockets through irradiation with a diode laser: a pilot study. J Clin Laser Med Surg. 1997;15(1):33-37.

12. Coluzzi DJ. Lasers and soft tissue curettage: an update. Compend Contin Educ Dent. 2002;23(11A):1104-1111.

13. Harashima T, Kinoshita J, Kimura Y, et al. Morphological comparative study on ablation of dental hard tissue at cavity preparation by Er: YAG and Er, CR: YSGG lasers. Photomed Laser Surg. 2005;23(1):52-55.

14. El-Housseiny AA, Jamjoum H. Evaluation of visual, explorer, and a laser device for detection of early occlusal caries. J Clin Pediatr Dent. 2001;26(1):41-48.

15. Tam LE, McComb D. Diagnosis of occlusal caries: Part II. Recent diagnostic technologies. J Can Dent Assoc. 2001;67(8):459-463.

16. Lussi A, Megert B, Longbottom C, et al. Clinical performance of a laser fluorescence device for detection of occlusal caries lesions. Eur J Oral Sci. 2001;109(1):14-19.

17. Pfarrer AM, Faller RV, Duschner H. Application of confocal laser scanning microscopy for studying demineralization and remineralization processes. In journal of dental research. 1996;75:543-543.

18. Samek O, Telle HH, Beddows DC. Laser-induced breakdown spectroscopy: a tool for real-time, in vitro and in vivo identification of carious teeth. BMC Oral Health. 2001;1(1):1.

19. Samraj RV, Indira R, Srinivasan MR. Recent advances in pulp vitality testing. Endodontology. 2003;15(1):14-19.

20. Park DS, Lee HJ, Yoo HM, et al. Effect of Nd: YAG laser irradiation on the apical leakage of obturated root canals: an electrochemical study. Int Endod J. 2001;34(4):318-21. 
21. Kimura Y, Wilder-Smith P, Matsumoto K. Lasers in endodontics: a review. Int Endod J. 2000;33(3):173-185.

22. Glockner K, Rumpler J, Ebeleseder K, et al. Intrapulpal temperature during preparation with the Er: YAG laser compared to the conventional burr: An in vitro study. J Clin Laser Med Surg. 1998;16(3):153-157.

23. Louw NP, Pameijer CH, Ackermann WD, et al. Pulp histology after Er: YAG laser cavity preparation in subhuman primates - A pilot study. SADJ. 2002;57(8):313-317.

24. Hossain M, Nakamura Y, Yamada Y, et al. Effects of Er, Cr: YSGG laser irradiation in human enamel and dentin: ablation and morphological studies. J Clin Laser Med Surg. 1999;17(4):155-159.

25. Martinez-Insua A, Dominguez LS, Rivera FG, et al. Differences in bonding to acid-etched or Er: YAG-laser-treated enamel and dentine surfaces. J Prosthet Dent. 2000;84(3):280-288.

26. Ceballos L, Osorio R, Toledano M, et al. Microleakage of composite restorations after acid or Er: YAG laser cavity treatment. Dent Mater. 2001;17(4):340-346.

27. Adams TC, Pang PK. Lasers in aesthetic dentistry. Dental Clinics. 2004;48(4):833-860.

28. Hegde MN, Hegde N, Bhat R. Gummy Smile Correction: Case Report. $J$ Laser Opt Photonics. 2014;1(103):2.

29. Strauss RA. Esthetics and Laser Surgery Laser-assisted bleaching: An update. ADA Council on Scientifi c Affairs. J Am Dent Assoc 1998;129:1484-1487.

30. Buchalla W, Attin T. External bleaching therapy with activation by heat, light or laser — a systematic review. Dental materials. 2007;23(5):586596.

31. Todea C, Kerezsi C, Balabuc C, et al. Pulp Capping-from Conventional to Laser-assisted Therapy (I). Journal of Oral Laser Applications. 2008;8(2):71-82.

32. Tominaga R. Effects of He-Ne laser irradiation on fibroblasts derived from scar tissue of rat palatal mucosa. Kokubyo Gakka Zasshi. 1990;57(4):580-594.

33. Loevschall H, Arenholtd-Bindslev D. Effect of low level diode laser irradiation of human oral mucosa fibroblasts in vitro. Lasers Surg Med. 1994;14(4):347-354.

34. Kurumada F. A study on the application of Ga-As semiconductor laser to endodontics. The effects of laser irradiation on the activation of inflammatory cells and the vital pulpotomy. Ohu Daigaku Shigakushi. 1990;17(3):233-244.

35. Kitsmaniuk ZD, Demochko VB, Popovich VI. The use of low energy lasers for preventing and treating postoperative and radiationinduced complications in patients with head and neck tumors. Vopr Onkol. 1992;38(8):980-986.

36. Dobson J, Wilson M. Sensitization of oral bacteria in biofilms to killing by light from a low-power laser. Arch Oral Biol. 1992;37(11):883-887.

37. Sarker S, Wilson M. Lethal photosensitization of bacteria in subgingival plaque from patients with chronic periodontitis. $J$ Periodontal Res. 1993;28(3):204-210.

38. Wilson M. Bacterial effect of laser light and its potential use in the treatment of plaque-related diseases. Int Dent J. 1994;44(2):181-189.

39. Walsh LJ. The current status of low level laser therapy in dentistry. Part 2. Hard tissue applications. Aust Dent J. 1997;42(5):302-306.

40. Dortbudak O, Haas R, Bernhart $\mathrm{T}$, et al. Lethal photosensitization for decontamination of implant surfaces in the treatment of periimplantitis. Clin Oral Implants Res. 2001;12(2):104-108.
41. Dougherty TJ. An update on photodynamic therapy applications. J Clin Laser Med Surg. 2002;20(1):3-7.

42. Fan KF, Hopper C, Speight PM, et al. Photodynamic therapy using mTHPC for malignant disease in the oral cavity. Int J Cancer. 1997;73(1):25-32.

43. Biel MA. Photodynamic therapy and the treatment of head and neck neoplasia. Laryngoscope. 1998;108(9):1259-1268.

44. Posten W, Wrone DA, Dover JS, et al. Low-level laser therapy for wound healing: Mechanism and efficacy. Dermatol Surg. 2005;31:334-340.

45. Ross G, Ross A. Low level lasers in dentistry. Gen Dent. 2008;56(7):629634.

46. Hargate G. A randomized double-blind study comparing the effect of 1072-nm light against placebo for the treatment of herpes labialis. Clin Exp Dermatol. 2006;31(5):638-641.

47. Ayoub AF, Siebert P, Moos KF, et al. A vision-based three-dimensional capture system for maxillofacial assessment and surgical planning. $\mathrm{Br} J$ Oral Maxillofac Surg. 1998;36(5):353-357.

48. Khambay B, Nebel JC, Bowman J, et al. 3D stereophotogrammetric image superimposition onto 3D CT scan images: The future of orthognathic surgery. A pilot study. Int J Adult OrthodOrthog Surg. 2002;17(4):331341 .

49. Moss JP, Ismail SF, Hennessy RJ. Three-dimensional assessment of treatment outcomes on the face. (179-82). Orthod Craniofac Res. 2003;6(Suppl 1):126-131.

50. McDonagh S, Moss JP, Goodwin P, et al. A prospective optical surface scanning and cephalometric assessment of the effect of functional appliances on the soft tissues. Eur J Orthod. 2001;23:115-126.

51. Hegde MN, Tahiliani D, Shetty A. The Art and Science of Lasers in dentistry.

52. Armida MM. Laser therapy and its applications in dentistry. Pract Odontol. 1989;10(3):9-16.

53. Peres F, Felino A, Carvalho JF. Analgesic effect of 904-nm laser radiation (IR) in oral surgery. Rev Port Estomatol Cir Maxilofac. 1985;26:205217.

54. Harazaki M, Isshiki Y. Soft laser irradiation effects on pain reduction in orthodontic treatment. Bull Tokyo Dent Coll. 1997;38(4):291-295.

55. Turhani D, Scheriau M, Kapral D, et al. Pain relief by single low-level laser irradiation in orthodontic patients undergoing fixed appliance therapy. Am J Orthod Dentofacial Orthop. 2006;130(3):371-377.

56. Mester AF, Snow JB, Shaman P. Photochemical effects of laser irradiation on neuritic outgrowth of olfactory neuroepithelial explants. Otolaryngol Head Neck Surg. 1991;105(3):449-456.

57. Solomon A, Lavie V, Ben-Bassat S, Belkin M, Schwartz M. New surgical approach to overcome the inability of injured mammalian axons to grow within their environment. J Neural Transplant Plast. 1991;2(3-4):243-8.

58. Beer F, Straß1 M, Wernisch J. Laser Safety. Journal of Oral Laser Applications. 2005;5(2).

59. Parker S. Laser regulation and safety in general dental practice. Br Dent J. 2007;202(9):523-532.

60. Hegde MN, Hegde ND, Nagesh SC. Lasers in management of endo-perio lesion-a case report. Archives of Oral Sciences \& Research. 2011;1:2151218.

61. Pohlhaus SR. Lasers in dentistry: minimally invasive instruments for the modern practice. Provider. 2012;501:211886. 